\title{
MYCO WELL D-ONE detection of Ureaplasma spp. and Mycoplasma hominis in sexual health patients in Wales
}

\author{
Daniel J. Morris ${ }^{1} \cdot$ Lucy C. Jones $^{1,2} \cdot$ Rebecca L. Davies $^{2} \cdot$ Kirsty Sands $^{1} \cdot$ Edward Portal $^{1} \cdot$ Owen B. Spiller $^{1}$ (D)
}

Received: 25 March 2020 / Accepted: 20 July 2020 / Published online: 28 July 2020

(C) The Author(s) 2020

\begin{abstract}
The genital mycoplasmas are a unique group of inherently antibiotic-resistant sexually transmitted bacteria, often associated with non-gonococcal urethritis and bacterial vaginosis. The MYCO WELL D-ONE is a culture-based assay that aims to detect these organisms whilst concurrently screening them for antibiotic resistance. Urine and/or swabs from 856 informed and consented participants attending Welsh sexual health clinics were subjected to MYCO WELL D-ONE analysis, alongside qPCR and culture titration methodologies to determine sensitivity, specificity, PPV, NPV and accuracy. Resistance was confirmed by CLSIcompliant susceptibility testing and genetic mechanisms determined. The MYCO WELL D-ONE displayed a sensitivity and specificity of $91.98 \%$ and $96.44 \%$ for the detection of Ureaplasma spp., with sensitivity and specificity values of $78.23 \%$ and 98.84\% for Mycoplasma hominis, compared with qPCR. Swabs harboured significantly greater bacterial loads than urine samples for both Ureaplasma spp. and M. hominis. Levofloxacin resistance rates, mediated by Ser83Leu mutation in ParC, for Ureaplasma spp. were $0.54 \%$. Tetracycline resistance rates, mediated by tet $(\mathrm{M})$, were $0.54 \%$ and $2 \%$ for Ureaplasma spp. and M. hominis, respectively; sequence analysis of tet(M)-positive Ureaplasma spp. and M. hominis strains isolated from a single individual confirmed separate resistance gene origins. The MYCO WELL D-ONE is a sensitive and specific assay for the detection of Ureaplasma spp. and M. hominis in genitourinary medicine samples, facilitating the accurate detection of these organisms within low-technology environments. While good for antibiotic resistance screening, accurate confirmation by MIC determination or molecular methods are required, and more optimally performed on urine samples.
\end{abstract}

Keywords Ureaplasma $\cdot$ Mycoplasma $\cdot$ Antimicrobial susceptibility $\cdot$ Assay validation $\cdot$ Bacterial load

\section{Introduction}

Ureaplasma spp. (Ureaplasma parvum and Ureaplasma urealyticum) and Mycoplasma hominis are often colloquially termed the 'genital mycoplasmas' (alongside Mycoplasma genitalium) due to their isolation from the human urogenital

Electronic supplementary material The online version of this article (https://doi.org/10.1007/s10096-020-03993-7) contains supplementary material, which is available to authorized users.

Owen B. Spiller

SpillerB@cardiff.ac.uk

1 School of Medicine, Division of Infection and Immunity, Department of Medical Microbiology, University Hospital of Wales, Cardiff University, Cardiff CF14 4XN, UK

2 Department of Integrated Sexual Health, Dewi Sant Hospital, Cwm Taf Morgannwg University Health Board, Pontypridd CF37 1LB, UK tract. All of the unique class Mollicutes, named from the Latin mollis (meaning soft) and cutis (meaning skin), lack a cell wall [1]. This idiosyncratic physiology, directly related to their reduced genome and subsequent limited biosynthetic capacity results in an inherent resistance to several groups of antibiotics, the $\beta$-lactams (including penicillins and cephalosporins), the glycopeptides, sulphonamides and trimethoprim $[2$, 3]. Consequently, treatment options for these unique bacteria are limited, restricted to four classes of antibiotics: fluoroquinolones, chloramphenicol, tetracyclines and macrolides. Further restrictions apply to pregnant females and neonates as administering all classes besides macrolides are contraindicated. Furthermore, M. hominis possesses a species-specific resistance to $14-$ and 15 -membered ring macrolides, mediated by a G2057A transition in its $23 \mathrm{~S}$ rRNA sequence [4], but remain susceptible to 16-membered ring macrolides such as Josamycin.

Though not recognised as equivalent to chlamydia, gonorrhoea or Mycoplasma genitalium as pathogens, these 
innately resistant bacteria are implicated in several urogenital pathologies, with Ureaplasma spp. being the only infectious agent in 10-20\% of non-gonococcal urethritis (NGU) cases [5], important as currently $45 \%$ of NGU are categorised as idiopathic [6]. In females, Ureaplasma spp. has been reported as associated with non-specific cervicitis (NSC) [7], endometritis [8] and preterm birth [9]. Whereas M. hominis is implicated in bacterial vaginosis (BV) [10] and pelvic inflammatory disease (PID) [11]. However, despite mounting evidence associating these organisms with disease, much controversy still surrounds them, owed to their isolation from seemingly healthy asymptomatic populations. However, although Chlamydia trachomatis presents as asymptomatic in most women, genital tract chlamydial infections are well accepted as the leading cause of PID, tubal factor infertility and ectopic pregnancy [12]. The dichotomy encompassing their classification as either 'commensal' or 'pathogen' means the recommendation to routinely screen for and treat these organisms is currently withheld pending more robust, better-designed studies that unequivocally solidify their role in disease [13]. Historically, studies presenting conflicting conclusions on the pathogenicity of Ureaplasma spp. and M. hominis failed to separate Ureaplasma into the 2 separate species or determine bacterial load, factors shown to influence the pathogenic potential of genital Mollicutes infection [14-16]. Consequently, researchers now suggest a risk-based treatment approach toward Ureaplasma spp. infection be taken-one considering Ureaplasma species, load and known risk factors (age, number of sexual partners etc.) - in cases of symptomatic NGU, devoid of more accepted etiological agents (i.e. chlamydia, gonorrhoea, M. genitalium, etc.) [17].

Traditional culture-based detection and enumeration methods for these organisms are complicated by their fastidious growth requirements and inability to grow to visual turbidity. Possessing a urea-metabolising enzyme, Ureaplasma spp. are unique among mycoplasmas, which are typically characterised by the substrate utilised for ATP generation: arginine or glucose (arginine in the case of M. hominis) [18]. Culture-based detection techniques employ Ureaplasma spp. ability to produce ammonium ions and increase $\mathrm{pH}$ through urea hydrolysis. Similarly, the arginine-dihydolase pathway produces ammonium ions and raises $\mathrm{pH}$ during the broth culture of M. hominis. Bespoke media exploit these substratespecific pathways for detection, visualized through the addition of a $\mathrm{pH}$ indicator (typically phenol red) and increased $\mathrm{pH}$ from bacterial growth being visualised by a non-turbid yellow to cerise-red colour change in the presence of beta-lactam antibiotics. More sensitive and specific approaches for the detection of these fastidious organisms are available through qPCR, which should be viewed as the 'gold-standard' detection method [19] which permits Ureaplasma speciation. Though more sensitive, qPCR-based approaches remain uneconomical and impractical for genital Mollicutes detection in low-resource laboratories with low to moderate sample volumes, where culture-based assays are better-suited. A key advantage of culture-based approaches is that they provide a viable isolate on which antimicrobial susceptibility testing (AST) can be performed. In commercially available diagnostic assays, this is done simultaneously alongside detection, through supplementing wells containing specific growth medium with breakpoint concentrations of antibiotics. Several commercially available detection kits have been utilised for detection and antimicrobial resistance reporting of Ureaplasma spp. and M. hominis: MYCOFAST revolutioN (ELiTech Diagnostic, France), Mycoplasma Duo and Mycoplasma SIR (Bio-Rad; Watford, U.K), Mycoplasma system plus (Liofilchem, Italy), Mycoplasma IST2 (Biomerieux, France). However, these assays fail to utilise CLSI (Clinical Laboratory Standards Institute) set international threshold concentrations of a standardised antibiotic panel, often leading to inappropriate and unvalidated reporting of resistance data $[20,21]$. Commercial assays also often fail to take into account the quantification of the bacterial inoculum tested, set by CLSI guidelines as $10^{4}-10^{5}$ colour changing units $/ \mathrm{mL}$ $(\mathrm{CCU} / \mathrm{mL})$, as higher bacterial loads have a demonstrable propensity to produce false positive results [22]. Alongside this, many kits do not separate Ureaplasma spp. and M. hominis coinfection, which complicates interpreting the AST, leading to the over-reporting of macrolide resistance due to $M$. hominis intrinsic macrolide resistance [20, 23]. In response, CPM SAS (Rome, Italy) developed the MYCO WELL DONE - the first commercially available assay that offers CLSI-compliant antibiotic breakpoints for AST of Ureaplasma spp. and M. hominis separately.

The present investigation was carried out to determine the sensitivity and specificity of the MYCO WELL D-ONE against gold-standard qPCR detection methods alongside culture detection in specialist culture media and CLSI-compliant broth microdilution confirmation of detected antimicrobial resistance.

\section{Materials and methods}

\section{Participant samples}

Urine and/or swabs (urethral, endocervical or high-vaginal) were collected from informed and consented participantsunder ethical approval (IRAS 230693)-from October 2017 to October 2018 attending Welsh sexual health walk-in clinics held at Dewi Sant hospital (Pontypridd), Keir Hardie Health Park (Merthyr Tydfil), or Ysbyty Cwm Cynon (Mountain Ash). A total of 983 samples were collected from 856 patients; 526 female patients, of which 122 provided both urine and endocervical swabs; 335 males, of which 5 provided both urine and urethral swabs. 


\section{Sample processing protocol}

For qPCR analysis, participant's urine samples were processed as follows: $2 \mathrm{~mL}$ of urine was transferred to a sterile $2 \mathrm{~mL}$ Eppendorf tube and centrifuged at $15,000 \times \mathrm{g}$ for $20 \mathrm{~min}$, supernatant removed and pellet frozen at $-86^{\circ} \mathrm{C}$ until extraction of genomic DNA using the QIAGEN QIACube automated extraction system (DNeasy Blood \& Tissue kit, bacterial pellet protocol with RNase treatment; elution into $100 \mu \mathrm{L}$ molecular grade water). Participant's swab samples were processed as follows: Copan Rayon swab samples were either taken by the clinician (endocervical) or self-taken by the participant (high vaginal), the swab was then suspended in $10 \mathrm{~mL}$ sterile saline (CPM S.A.S.), $2 \mathrm{~mL}$ of the swab suspension was centrifuged and processed for DNA extraction as for urine above. DNA extracts were stored at $-86{ }^{\circ} \mathrm{C}$ until batch analysed by quantitative PCR. Concurrently, the MYCO WELL D-ONE assay (purchased from CPM S.A.S., Rome, Italy) was processed as per manufacturer's instructions. Briefly, $150 \mu \mathrm{L}$ of swab- (swab resuspended in $10 \mathrm{~mL}$ saline) or urine-inoculated saline $(200 \mu \mathrm{L}$ urine added to $10 \mathrm{~mL}$ saline) was transferred to each well, topped with two drops of paraffin oil to create an anaerobic environment and stop evaporation and incubated at $37{ }^{\circ} \mathrm{C}$ and ambient $\mathrm{CO}_{2}$. Additionally, alongside the MYCOWELL D-ONE and qPCR assays, a culture titration assay was implemented to concurrently detect and determine the bacterial load of each swab/urine-inoculated saline sample. The culture titration assay for Ureaplasma has been previously described [22] and was modified to include the additional titration of $M$. hominis in parallel using M. hominis-specific medium (MHSM) purchased from CPM SAS (Rome, Italy). Briefly, titration and breakpoint screening in antibiotics were set up in sterile 96well flat-bottomed microtitre plates receiving $10 \mu \mathrm{L}$ of sample-inoculated sterile saline containing $90 \mu \mathrm{L}$ of Ureaplasma or M. hominis-specific medium prior to 1:10 dilution series in the same medium to a final $10^{-7}$ dilution. Uninoculated medium was included in parallel and acted as a negative control for each serial dilution; the plates were then sealed with transparent adhesive sealing tape (Elkay: Basingstoke, United Kingdom), and were incubated at $37^{\circ} \mathrm{C}$ and ambient $\mathrm{CO}_{2}$. Alongside this culture titration methodology, $20 \mu \mathrm{L}$ of undiluted urine was pipetted into $180 \mu \mathrm{L}$ USM and MHSM and incubated at $37^{\circ} \mathrm{C}$ and read at various intervals up to $72 \mathrm{~h}$ post-incubation; this latter method was included because $10 \mu \mathrm{L}$ of 1:500 diluted urine in sterile saline was 15 -fold less than the amount inoculated into the MYCO WELL D-ONE and has an overall limit of detection of $10^{3}$ CCU per mL. Finally, $5 \mu \mathrm{L}$ of inoculated sterile saline solution was pipetted directly onto the surface of US1 agar (Mycoplasma Experience) and incubated at $37^{\circ} \mathrm{C}$ and ambient $\mathrm{CO}_{2}$. Positives were determined through the presence of a classic 'fried-egg' morphology under light microscopy for $M$. hominis, and red $\mathrm{pH}$ colour change in the media with tiny granular Ureaplasma colonies.

\section{Molecular analysis}

BioRad Laboratories (Watford, UK) CFX96 Touch Real-Time PCR thermocycler and BioRad Maestro software was used to run the assays. SsoAdvanced Universal Probes Supermix for hydrolysis probes (BioRad Laboratories) and 96-well plates and optical clear adhesive seals (BioRad Laboratories) were used. Total volume of each reaction was $20 \mu \mathrm{L}$, comprised of the following: $10 \mu \mathrm{L} 2 \mathrm{x}$ mastermix, $0.25 \mathrm{pmol} / \mu \mathrm{L}$ Ureaplasma parvum forward primer, $0.25 \mathrm{pmol} / \mu \mathrm{L}$ Ureaplasma parvum reverse primer, $0.01 \mathrm{pmol} / \mu \mathrm{L}$ Ureaplasma parvum probe; $0.25 \mathrm{pmol} / \mu \mathrm{L}$ Ureaplasma urealyticum forward primer, $0.25 \mathrm{pmol} / \mu \mathrm{L}$ Ureaplasma urealyticum reverse primer, $0.01 \mathrm{pmol} / \mu \mathrm{L}$ Ureaplasma urealyticum probe; $0.25 \mathrm{pmol} / \mu \mathrm{L}$ Mycoplasma hominis forward primer, $0.25 \mathrm{pmol} / \mu \mathrm{L}$ Mycoplasma hominis reverse primer, $0.01 \mathrm{pmol} / \mu \mathrm{L}$ Mycoplasma hominis probe, with the remainder molecular grade water. Genomic copy equivalents were determined against a 6-point standard curve $\left(10^{6}-10^{1}\right.$ copies) of diluted plasmid containing concatamers of the primer and probe targets separated by $30 \mathrm{bp}$ intervening sequences (synthesized by GenScript) and accurately quantified by Life Technologies Qubit fluorometer DNA quantification system. Primers and Taqman hydrolysis probes for Ureaplasma parvum and Ureaplasma urealyticum were previously clinically validated [24] as were primers and Taqman hydrolysis probes for Mycoplasma hominis [25]. Bio-Rad CFX96 cycling conditions were as follows: initial activation and denaturation $95^{\circ} \mathrm{C}$ for $5 \mathrm{~min}$, next 45 cycles of $95^{\circ} \mathrm{C}$ for $15 \mathrm{~s}$ and $60^{\circ} \mathrm{C}$ for $15 \mathrm{~s}$. Readings were acquired in between cycles on channels FAM, HEX, ROX and CY5. Data was analysed on Bio-Rad CFX Maestro software. Presence of amplification inhibitors were assessed using QIAGEN Quantinova as per manufacturer's instructions. Primers and probes are listed in Supplementary Table 1.

\section{CLSI-compliant break-point antimicrobial susceptibil- ity testing}

Analysis of putative resistant isolates was conducted in accordance with CLSI M43A(21) using a previously published methodology for breakpoint analysis for Ureaplasma spp. isolates [22]. The method was modified to include additional antibiotics, alongside utilising MHSM for the breakpoint screening of M. hominis isolates. Isolates were screened against the CLSI guideline concentrations of antibiotic. Isolates were only screened against antibiotics if they had shown supposed resistance to that antibiotic on the MYCO WELL D-ONE assay. All antibiotics were purchased from Sigma-Aldrich (Dorset, UK) and supplied as or reconstituted 
to $1 \mathrm{mg} / \mathrm{mL}$ stock solutions, prior to further dilution in the appropriate media (USM/MHSM) to achieve CLSIcompliant concentrations for AST.

\section{Whole genome sequencing}

All isolates confirmed to be antibiotic resistant by CLSIcompliant methods were scaled up to $500 \mathrm{~mL}$ culture, pelleted at $13,000 \times \mathrm{g}$ for $3 \mathrm{~h}$ and DNA extracted using the QIAcube and QIAGEN reagents for Gram-negative protocol described above. Following extraction of DNA, Qubit 4.0 (Life Technologies) fluorometric analysis verified a sufficient concentration of DNA was isolated $(1-8 \mathrm{ng} / \mu \mathrm{L})$. Briefly, whole genome sequencing was performed using a Nextera XT library preparation and sequenced with a V3 chemistry on an Illumina MiSeq platform. The bioinformatics pipeline was comprised of 3 main processes; (1) QC pipeline to validate and trim the raw sequence reads: FastQC and Trimgalore [26, 27]; (2) whole genome assembly and mapping: Flash, SPAdes, BWA, pilon and quast [28-32]; (3) whole genome annotation and profiling of genetic determinants using a combination of available software (using both fastq and de novo assembled reads): prokka, NCBI BLAST, kmerfinder, CARD, srst2, ARG-ANNOT and VFDB [33-39]. Assembled contigs were further analysed utilising Geneious sequence analysis software (BioMatters Ltd., New Zealand) and aligned and assessed against antibiotic susceptible reference sequences for the identification of mobile genetic elements or point mutations.

\section{Statistical analysis}

All statistical analyses were performed using GraphPad Prism version 7 (GraphPad Software). Significance was only attributed to comparisons where $P$ value $<0.05$.

\section{Results}

\section{Assay sensitivity and specificity}

The multiplex qPCR implemented for the detection of Ureaplasma spp. and M. hominis infections was utilised as the 'gold standard' reference methodology to determine the sensitivity and specificity of the MYCO WELL D-ONE assay detecting these organisms (Tables 1 and 2). For the detection of Ureaplasma spp. from 983 samples, 413 qPCR positive samples, 515 qPCR negative samples, 19 false positive (qPCR negative, MYCO WELL D-ONE positive) samples and 26 false negative (qPCR positive, MYCO WELL DONE negative) samples were identified, when comparing MYCO WELL D-ONE data with that of qPCR. Utilising these data, the sensitivity and specificity for the detection of
Ureaplasma infection for the MYCO WELL D-ONE is calculated to be $91.98 \%$ and $96.44 \%$, respectively. The positive predictive value (PPV) and negative predictive value (NPV) of the MYCO WELL D-ONE to determine Ureaplasma infection was $95.6 \%$ and $93.47 \%$, respectively, with an accuracy of $94.4 \%$. For the detection of $M$. hominis, a total of 97 true positive samples, 849 true negative samples, 10 false positive samples and 27 false negative samples were identified when comparing MYCO WELL D-ONE data with that of qPCR. The sensitivity and specificity for the detection of $M$. hominis infection for the MYCO WELL D-ONE is calculated to be $78.23 \%$ and $98.84 \%$, respectively. The positive predictive value (PPV) and negative predictive value (NPV) of the MYCO WELL D-ONE to determine Mycoplasma hominis infection was $90.65 \%$ and $96.92 \%$, respectively, with an accuracy of $96.2 \%$.

\section{Antimicrobial screening accuracy}

All samples displaying a positive result in the highest concentration of antibiotic (set at the CLSI determined breakpoint concentrations) were further investigated for antimicrobial resistance utilising the methodology outlined in Beeton et al. [22]. The guidance included with the MYCO WELL DONE assay stipulates that if the $\geq 10^{5}$ well is positive, any positivity in resistance determining wells is invalid and is to be confirmed by other means. In total, 106 Ureaplasma spp. isolates were culture purified through serial dilution in specialist media and screened for antibiotic resistance against one or more antibiotic, due to positivity displayed in AST wells of the MYCO WELL D-ONE. However, these represent all strains that showed colour change for any antibiotic at $72 \mathrm{~h}$, and adherence to manufacturer's guidelines (only consider those that do not show colour change for the $\geq 10^{5}$ bacterial load and disregard antibiotic resistance that emerges at timepoints later than the initial positive Mollicute identification) greatly reduced the number of false positives identified. Uncorrected putative resistance included 69 for erythromycin, 25 for josamycin, 30 for tetracycline, 32 for levofloxacin and 23 for moxifloxacin. Of those tested, 94 were excluded due to a positive $\geq 10^{5}$ MYCO WELL D-ONE well. By manufacturer's guidelines, these samples would have required confirmation following dilution and retesting or by alternative method. The 12 remaining isolates were predicted to have been tested at a bacterial load of $10^{4} \mathrm{CCU} / \mathrm{mL}$ with various combinations of positive resistance wells; however, antimicrobial resistance was only seen for 4 of these after 12-24 h additional incubation and must also be excluded (Fig. 1). Isolates were screened against one or more antibiotic; 3 against erythromycin, 2 against josamycin, 2 against tetracycline, 3 against levofloxacin and 4 against moxifloxacin. Of these 8 isolates determined to be resistant by MYCOWELL D-ONE, two (1 levofloxacin-resistant and 1 tetracycline-resistant) were 
Table 1 Sensitivity, specificity, positive predictive value, negative predictive value and accuracy for MYCO WELL D-ONE detection of Ureaplasma spp.

\begin{tabular}{lllllll}
\hline $\begin{array}{l}\text { Detection of } \\
\text { Ureaplasma } \text { spp. }\end{array}$ & $\begin{array}{l}\text { Total } \\
\text { sample } \\
\text { number }\end{array}$ & Sensitivity & Specificity & $\begin{array}{l}\text { Positive } \\
\text { predictive } \\
\text { value }\end{array}$ & $\begin{array}{l}\text { Negative } \\
\text { predictive } \\
\text { value }\end{array}$ & Accuracy \\
\hline Overall & 983 & $91.98 \%$ & $96.44 \%$ & $95.60 \%$ & $93.47 \%$ & $94.40 \%$ \\
Swab & 297 & $92.05 \%$ & $93.39 \%$ & $98.29 \%$ & $88.98 \%$ & $92.59 \%$ \\
Urine & 686 & $91.94 \%$ & $99.27 \%$ & $98.82 \%$ & $94.91 \%$ & $96.36 \%$ \\
Male & 335 & $85.71 \%$ & $99.62 \%$ & $98.36 \%$ & $96.35 \%$ & $96.72 \%$ \\
Female & 648 & $93.14 \%$ & $93.31 \%$ & $95.15 \%$ & $90.61 \%$ & $93.21 \%$ \\
\hline
\end{tabular}

Relative to qPCR detection of Ureaplasma spp. infection across sample types and genders. The MYCO WELL DONE was most sensitive for the detection of Ureaplasma spp. infections in females (93.14\%), particularly for swab samples $(92.05 \%)$. Specificity and accuracy were highest for male (99.62\% and $96.72 \%$, respectively) and urine samples $(99.29 \%$ and $96.36 \%$, respectively) confirmed to be resistant when subjected to CLSI compliant AST. A further 2 resistant isolates (1 levofloxacin-resistant and 1 tetracycline-resistant) were discovered following screening of isolates that possessed a positive $>10^{5} \mathrm{CCU} / \mathrm{mL}$ well, indicating that resistance confirmation should be determined by other means or retested following dilution. In total, 2 levofloxacin-resistant strains (isolates DF99 and KF86) and 2 tetracycline-resistant strains (isolates DF145 and DF28) were identified to be truly resistant. These isolates were scaled up and analysed for whole genome sequencing.

For M. hominis, 14 isolates were identified as resistant on the MYCO WELL D-ONE assay (Fig. 2); however, the assay does not indicate bacterial load for this species to determine if they are compliant with CLSI guidelines. However, for 7 of these isolates, antibiotic resistance was only detected after 13$28 \mathrm{~h}$ after initial organism's identification and were therefore excluded as directed by manufacturer's guidelines. Therefore, the remaining putative resistant isolates were culture purified and screened against one or more antibiotics; 4 against clindamycin, 1 against josamycin, 1 against tetracycline, 2 against levofloxacin and 2 against moxifloxacin. However, only a single $M$. hominis isolate was found to be tetracycline resistant (isolate DF28) following comprehensive confirmatory testing. AST analysis of the remaining $M$. hominis isolates identified a further tetracycline-resistant isolate (KM14) missed by the MYCO WELL D-ONE assay (Fig. 2).

\section{Mechanisms of antimicrobial resistance determination}

Whole genome sequencing of resistant isolates revealed the genetic elements and somatic mutations conferring the antibiotic resistance to the isolated organism (Table 3). Both Ureaplasma spp. isolated and determined to be levofloxacin resistant ( $\mathrm{MIC}=4 \mathrm{mg} / \mathrm{L}$ ) possessed the amino acid substitution Ser83Leu (serine to leucine substitution) in the parC gene of the quinolone resistance determining region (QRDR). The tetracycline-resistant Ureaplasma spp. isolated both possessed the Tn916 tet $(M)$ conjugated transposon as did the two tetracycline-resistant $M$. hominis isolates. The patient identified as DF28 yielded both a tet(M)-positive $U$. parvum strain and a tet(M)-positive $M$. hominis strain; however, direct comparison of the genes found a difference of 24/1920 nucleotides (19 of which were clustered in close proximity; Fig. 3), indicating completely separate origins for these strains coincidental in their infection of the same patient.
Table 2 Sensitivity, specificity, positive predictive value, negative predictive value and accuracy for the MYCO WELL D-ONE detection of Mycoplasma hominis

\begin{tabular}{lllllll}
\hline $\begin{array}{l}\text { Detection of } \\
\text { M.hominis }\end{array}$ & $\begin{array}{l}\text { Total sample } \\
\text { number }\end{array}$ & Sensitivity & Specificity & $\begin{array}{l}\text { Positive } \\
\text { predictive } \\
\text { value }\end{array}$ & $\begin{array}{l}\text { Negative } \\
\text { predictive } \\
\text { value }\end{array}$ & Accuracy \\
\hline Overall & 983 & $78.23 \%$ & $98.84 \%$ & $90.65 \%$ & $96.92 \%$ & $96.24 \%$ \\
Swab & 297 & $78.57 \%$ & $97.93 \%$ & $89.80 \%$ & $95.16 \%$ & $94.28 \%$ \\
Urine & 686 & $77.46 \%$ & $99.35 \%$ & $93.22 \%$ & $97.45 \%$ & $97.09 \%$ \\
Male & 335 & $92.86 \%$ & $99.69 \%$ & $92.86 \%$ & $99.69 \%$ & $99.40 \%$ \\
Female & 648 & $76.36 \%$ & $98.33 \%$ & $90.32 \%$ & $95.32 \%$ & $94.60 \%$ \\
\hline
\end{tabular}

Relative to qPCR detection of $M$. hominis infection across sample types and genders. The MYCO WELL D-ONE was most sensitive for the detection of $M$. hominis infections in males $(92.86 \%)$. Specificity and accuracy were highest for male $(99.69 \%$ and $99.40 \%$, respectively) and urine samples (99.35\% and $97.09 \%$, respectively) 


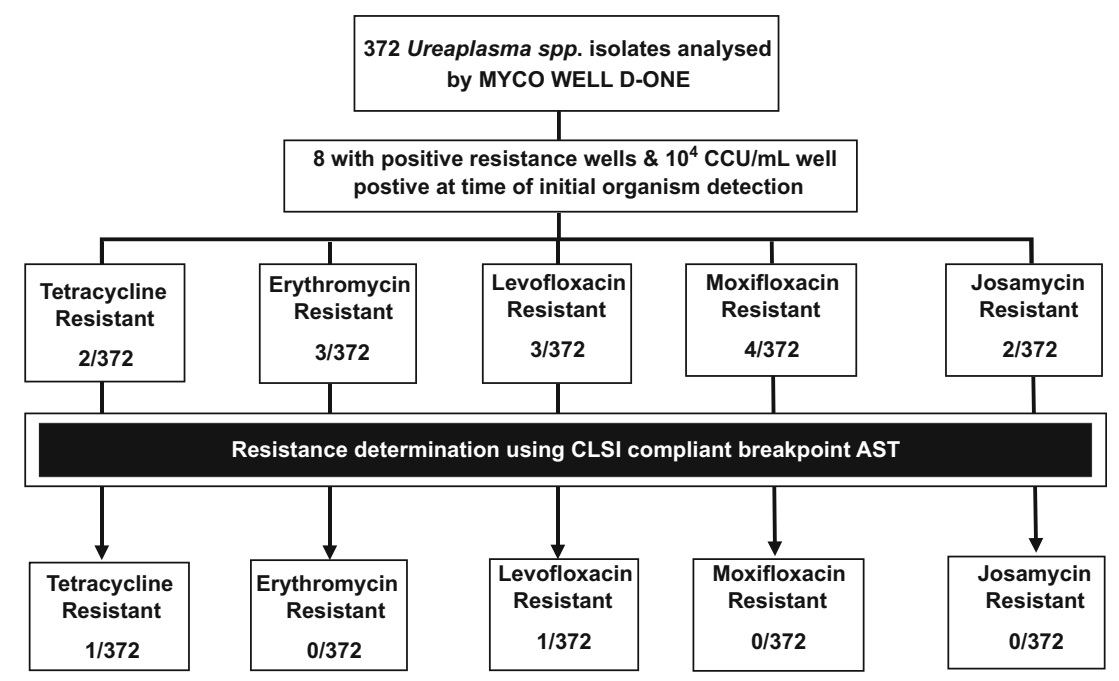

Fig. 1 Flow chart displaying CLSI-compliant AST of Ureaplasma spp. presumptively identified as resistant by MYCO WELL D-ONE. The MYCO WELL D-ONE was not found to significantly over-report resistance ( $p>0.05$; Fisher's exact test). For isolates that were identified by the assay as being resistant (without additional incubation post-organism

\section{Bacterial load comparison for sample type}

It was observed that analysis of Ureaplasma spp. samples from swabs routinely were identified as having $>10^{5} \mathrm{CCU} /$ $\mathrm{mL}$ bacterial loads by MYCO WELL D-ONE identification wells. Accurate bacterial load quantification by titration in selective media was used to compare data for different sample types and genders for both and Ureaplasma spp. and $M$. hominis. Given that these dilutions were made from samples suspended in $10 \mathrm{~mL}$ of sterile saline initially, the limit of detection for the culture titration methodology would be $10^{3} \mathrm{CCU} / \mathrm{mL}$. Therefore, where this method failed to grow isolates, that were detected in parallel either via the single well inoculation of undiluted urine or detection of colonies on inoculated US1 agar, these were recorded to have a bacterial detection) and at a bacterial load of $10^{4} \mathrm{CCU} / \mathrm{mL}$, one isolate was confirmed as resistant to levofloxacin and one isolate to tetracycline. Further resistant Ureaplasma spp. isolates were found (1 levofloxacin and 1 tetracycline) though are omitted from this chart as they were identified as $\geq 10^{5} \mathrm{CCU} / \mathrm{mL}$ by the initial assay screening

load of $<10^{3} \mathrm{CCU} / \mathrm{mL}$ for analysis. Ureaplasma spp. were detected in 422 samples: 168 swab samples and 254 urine samples; and for M. hominis, 91 samples were culturepositive; 48 swab samples and 43 urine samples. Positive samples were divided into those greater, and those less, than $10^{5} \mathrm{CCU} / \mathrm{mL}$ (CLSI set limit for accurate AST) and further sub-categorised by sample type. For Ureaplasma-positive urine samples, $5.9 \%(15 / 254)$ were $>10^{5} \mathrm{CCU} / \mathrm{mL}$, with $94.1 \%$ of samples having Ureaplasma load of $<10^{5} \mathrm{CCU} /$ $\mathrm{mL}$. While for swab samples, $55.9 \%$ of Ureaplasma positives had a bacterial load of $>10^{5} \mathrm{CCU} / \mathrm{mL}$, with the remainder of positives (44.1\%) having Ureaplasma load of $<10^{5} \mathrm{CCU} / \mathrm{mL}$ (Fig. 4a). The prevalence of Ureaplasma load of $>10^{5} \mathrm{CCU} /$ $\mathrm{mL}$ captured on swab samples is significantly higher than that of urine samples, for Ureaplasma-positive patients
Fig. 2 Flow chart displaying CLSI-compliant AST of $M$. hominis presumptively identified as resistant by MYCO WELL DONE. The MYCO WELL D-

ONE over-reported clindamycin resistance ( $p=0.05$; Fisher's exact test). One further tetracyclineresistant $M$. hominis isolate was found although it was missed by the initial assay screening

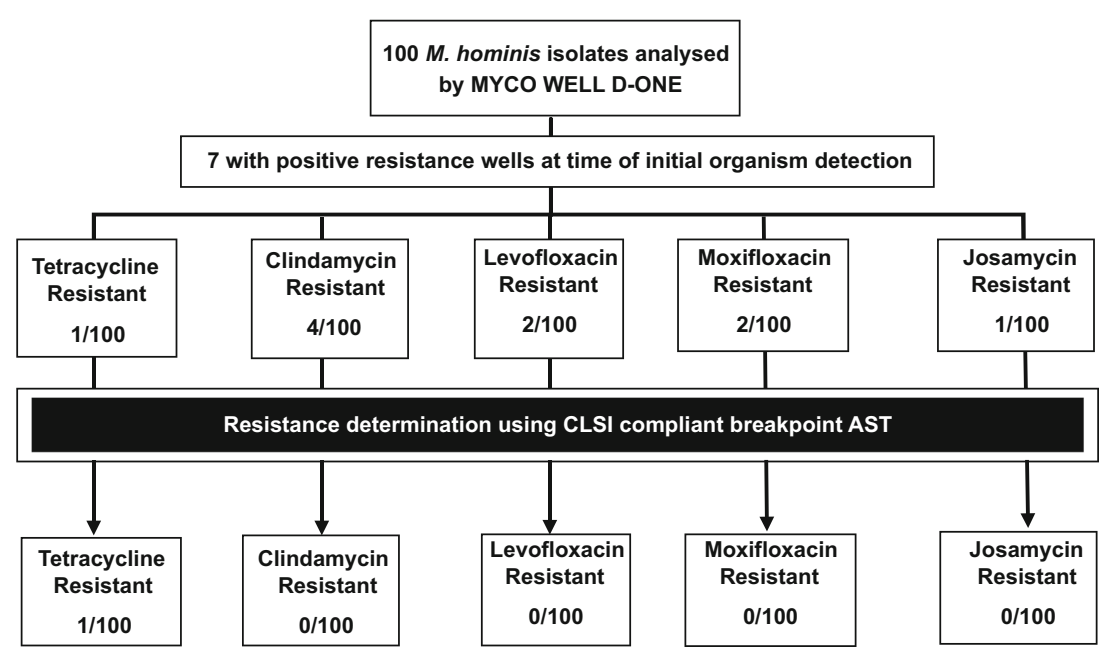




\begin{tabular}{|c|c|c|}
\hline Mycoplasma & 721 & 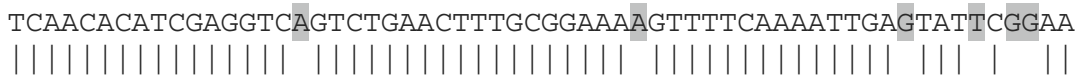 \\
\hline Ureaplasma & 721 & TCAACACATCGAGGTCCGTCTGAACTTTGCGGAAATGTTTTCAAAATTGAATATACAAAA \\
\hline Mycoplasma & 781 & 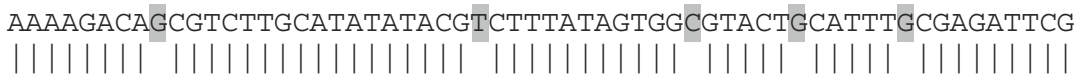 \\
\hline Ureaplasma & 781 & AAAAGACAACGTCTTGCATATATACGCCTTTATAGTGGAGTACTACATTTACGAGATTCG \\
\hline Mycoplasma & 841 & $\begin{array}{l}\text { GTTAGAATATCGGAAAGGAAAAAATAAAATTACAGAAATGATACTTCAATAAATGGT } \\
\text { (a) }\end{array}$ \\
\hline Ureaplasma & 841 & GTTAGAGTATCAGAAAAAGAAAAAATAAAAGTTACAGAAATGTATACTTCAATAAATGGT \\
\hline Mycoplasma & 901 & $\begin{array}{l}\text { GAATTATGTAAAATCGATAAGGCTTATTCTGGAGAAATTGTTATTTTGC } \\
|\||||||||||||||||||||||||||||||||||||||||||||||\end{array}$ \\
\hline Ureaplasma & 901 & GAATTATGTAAGATTG \\
\hline
\end{tabular}

Fig. 3 Nucleotide alignment of the tet(M) gene found in the U. parvum and $M$. hominis strains, both co-incidentally isolated from the same patient. Shown here are nineteen of the twenty-four mismatches in nucleotide identity were clustered in a 180 nucleotide stretch in the middle of the

( $p<0.0001$; Fisher's exact test). Analysis of M. hominis-positive samples (Fig. 4b) similarly revealed swabs possess greater bacterial loads than $M$. hominis-positive urine samples. $M$. hominis-positive swab samples with a bacterial load of $>$ $10^{5} \mathrm{CCU} / \mathrm{mL}$ accounted for $40 \%$ of total swab-positives (19/ 48); $60 \%$ of swab-positives had a M. hominis load of < $10^{5} \mathrm{CCU} / \mathrm{mL}$ (29/48). Whereas $93 \%$ of $M$. hominis-positive urine samples had a bacterial load $<10^{5} \mathrm{CCU} / \mathrm{mL}(40 / 43)$ with $7 \%$ of positive urines having a $M$. hominis load of $>$ $10^{5} \mathrm{CCU} / \mathrm{mL}$. Fisher's exact test determined that $M$. hominispositive swab samples have a statistically significant greater incidence of bacterial loads exceeding $10^{5} \mathrm{CCU} / \mathrm{mL}$, when compared with $M$. hominis loads of urine-positive samples $(p=0.0004)$. Therefore, these assays are much better suited to urine samples and direct AST evaluation may not be possible on resuspended swabs without modification of the protocol to include additional dilution.

In total, 127 patients provided paired swab and urine samples, comprised of the following: 122 endocervical swaburine pairings from female patients and 5 urethral swaburine pairings from male patients, 71 patients were positive
1920 nucleotide open reading frame, confirming different origins for these genes and not transfer between these two co-infecting species

for Ureaplasma spp. and 21 patients M. hominis-positive by culture titration. The limit of detection for the culture titration method was $10^{3} \mathrm{CCU} / \mathrm{mL}$. Therefore, as above, detection by culture methods run in parallel not subjected to these limitations are listed as $<10^{3} \mathrm{CCU} / \mathrm{mL}$ and where no organism was detected (M. hominis only) the matching negative culture is shown as 0 (Fig. 5). For Ureaplasma spp. (Fig. 5a), in 38\% of cases, swabs had bacterial loads equal to or 10 times greater than their urine counterparts. Whereas bacterial loads between 100 and 1000 times higher in swab samples, compared with their respective urines, were observed in $43.7 \%$ of Ureaplasma-positive samples. Additionally, swabs with Ureaplasma loads between $10^{3}$ and $10^{5}$ and $10^{6}-10^{7}$ times greater than their urine counterpart samples were observed in $15.5 \%$ and $2.8 \%$ of Ureaplasma-positive patients, respectively. A paired $t$ test between paired urine and swab samples displays swabs have significantly higher bacterial loads than their respective urine samples $(p=0.0255)$. For M. hominispositive paired patient samples (Fig. 5b), 76.2\% (16/21) possessed swab-positive cultures with bacterial loads equal to, or greater than, their respective urine samples. For $9.5 \%(2 / 21)$ of
Table 3 Details of resistant isolates

\begin{tabular}{lllll}
\hline Sample number & Antibiotic & MIC $(\mu \mathrm{g} / \mathrm{mL})$ & Resistance mechanism & Species \\
\hline DF99 & Levofloxacin & 4 & Ser83Leu ParC mutation & U. parvum \\
KF86 & Levofloxacin & 4 & Ser83Leu ParC mutation & U. parvum \\
DF28 & Tetracycline & 128 & Tn916 tet $(M)^{\text {a }}$ & $U$. parvum \\
DF145 & Tetracycline & 32 & Tn916 tet $(M)$ & U. parvum \\
DF28 & Tetracycline & 64 & Tn916 tet $(M)^{\text {a }}$ & M. hominis \\
KM14 & Tetracycline & 64 & Tn916 tet $(M)$ & M. hominis \\
\hline
\end{tabular}

MIC determined under CLSI-compliant conditions are given alongside the underlying genetic mechanism of resistance identified by whole genome sequencing analysis

${ }^{\mathrm{a}}$ tet $(M)$ gene sequence from isolated U. parvum and M. hominis strains differed by $24 / 1920$ nucleotides and therefore originated from different sources 

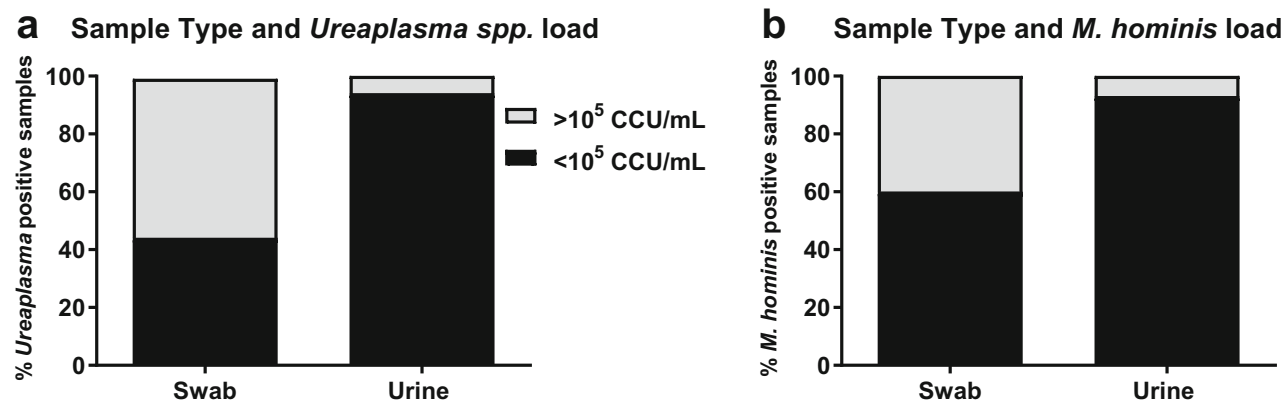

Fig. 4 Bacterial loads for Ureaplasma spp. (a) or M. hominis (b) in swab or urine samples. Bacterial loads from urine samples were more frequently amenable for AST, based on CLSI guidelines, for $<10^{5}$ $\mathrm{CCU} / \mathrm{ml}$ (black fraction of the bar). a For Ureaplasma-positive urine samples $5.9 \%$ possessed a load $>10^{5} \mathrm{CCU} / \mathrm{mL}$ (grey fraction of the bar), whereas for Ureaplasma-positive swab samples, $55.9 \%$ possessed a load $>10^{5} \mathrm{CCU} / \mathrm{mL}$. The prevalence of a Ureaplasma load of $>10^{5}$ $\mathrm{CCU} / \mathrm{mL}$ captured on swab samples was significantly higher than that of

M. hominis-positive patients with paired samples, M. hominis could only be recovered from urine samples and was undetectable in the complementary swab sample. Conversely, for a further $9.5 \%(2 / 21)$ of $M$. hominis-positive patients with paired samples, $M$. hominis was undetectable in the urine samples, but was recovered from the complementary swab samples. The remaining sample $(1 / 21)$, accounting for $4.75 \%$ of total M. hominis-positive paired samples, possessed a urine sample with a greater bacterial load than its swab counterpart. Swab samples had M. hominis loads equal to, or 10 times higher, in $42.9 \%$ of cases $(9 / 21)$. Swab samples with $100-1000$ times higher, and swab samples with $10^{4}-10^{5}$ times higher M. hominis loads accounted for $23.8 \%$ and $14.3 \%$ of paired samples, respectively. Additionally, $9.5 \%$ of paired swab samples had bacterial loads $10^{6}-10^{9}$ times higher, than their respective urine samples. However, in two instances, both comprising $4.5 \%$ each of the total M. hominis-positive

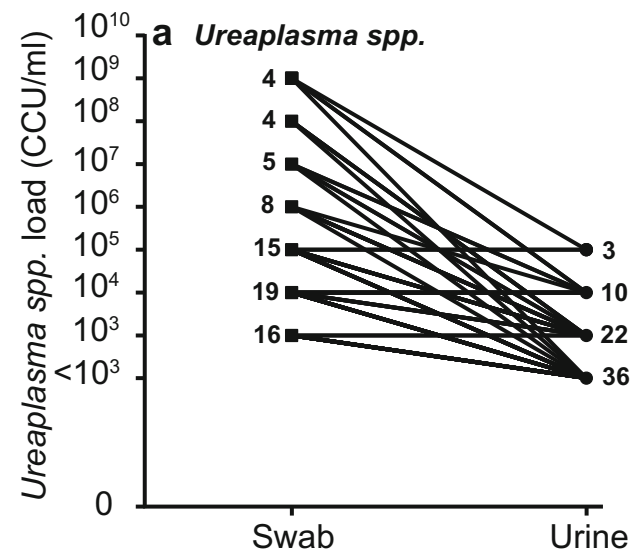

Fig. 5 Bacterial load comparison for matched Ureaplasma-positive (a) or M. hominis-positive (b) patient samples. a All paired Ureaplasmapositive samples possessed bacterial loads equal to or greater their urine counterparts. Statistical analysis revealed swabs to possess significantly greater Ureaplasma loads than urines ( $p=0.0255$; paired $t$ test). b $76.2 \%$ of paired M. hominis-positive samples possessed bacterial loads equal to

paired samples, urine samples had a higher bacterial load than their swab counterparts, one with a bacterial load 100 times greater and the other with a load $10^{6}$ times higher. Finally, though swab samples more frequently had greater bacterial loads than their respective urine samples, insufficient matched samples were available for these differences to achieve a statistical difference by a paired $t$ test $(p=0.0939)$.

\section{Time to detection from assay inoculation}

A limitation of all non-molecular-based detection and AST testing assays is the incubation time. Therefore, we analysed time to first detection for MYCO WELL D-ONE, alongside the culture titration methodology, was also recorded following incubation (Fig. 6). Plates were inoculated immediately following receipt of the sample at the hospital in which they were collected and placed in an incubator in $3 \mathrm{~h}$ or less. Samples

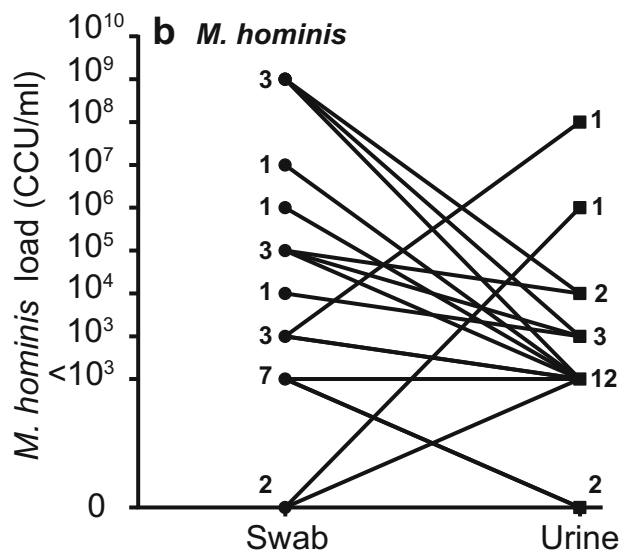

or greater their urine counterparts. However, 2 urine samples detected $M$. hominis where swab samples did not and 2 swab samples detected $M$. hominis in patients with negative culture results from urine. A universal trend of lower bacterial load in urine compared to matched swabs was not always seen for this organism. Statistical analysis of matched M. hominispositive samples failed to achieve significance $(p=0.0939$; paired $t$ test $)$ 
Fig. 6 Bar and whisker graphs displaying the min-max detection times for Ureaplasma spp. and $M$. hominis. Samples from males and females are examined separately comparing the MYCO WELL DONE assay to culture titration assay in specialist media. Mean values are represented by + symbol. Time to detection of Ureaplasma spp. in female samples was $28.14 \mathrm{~h}$ (culture titration) and 27.57 (MYCO WELL DONE) (a) and $34.09 \mathrm{~h}$ in males was for both assays (b). Time to detection of $M$. hominis in females was 43.26 and $43 \mathrm{~h}$ for MYCO WELL D-ONE and culture titration, respectively $(\mathbf{c})$, and $46.25 \mathrm{~h}$ in male samples (d).

There was no significant difference in time to detection between assays
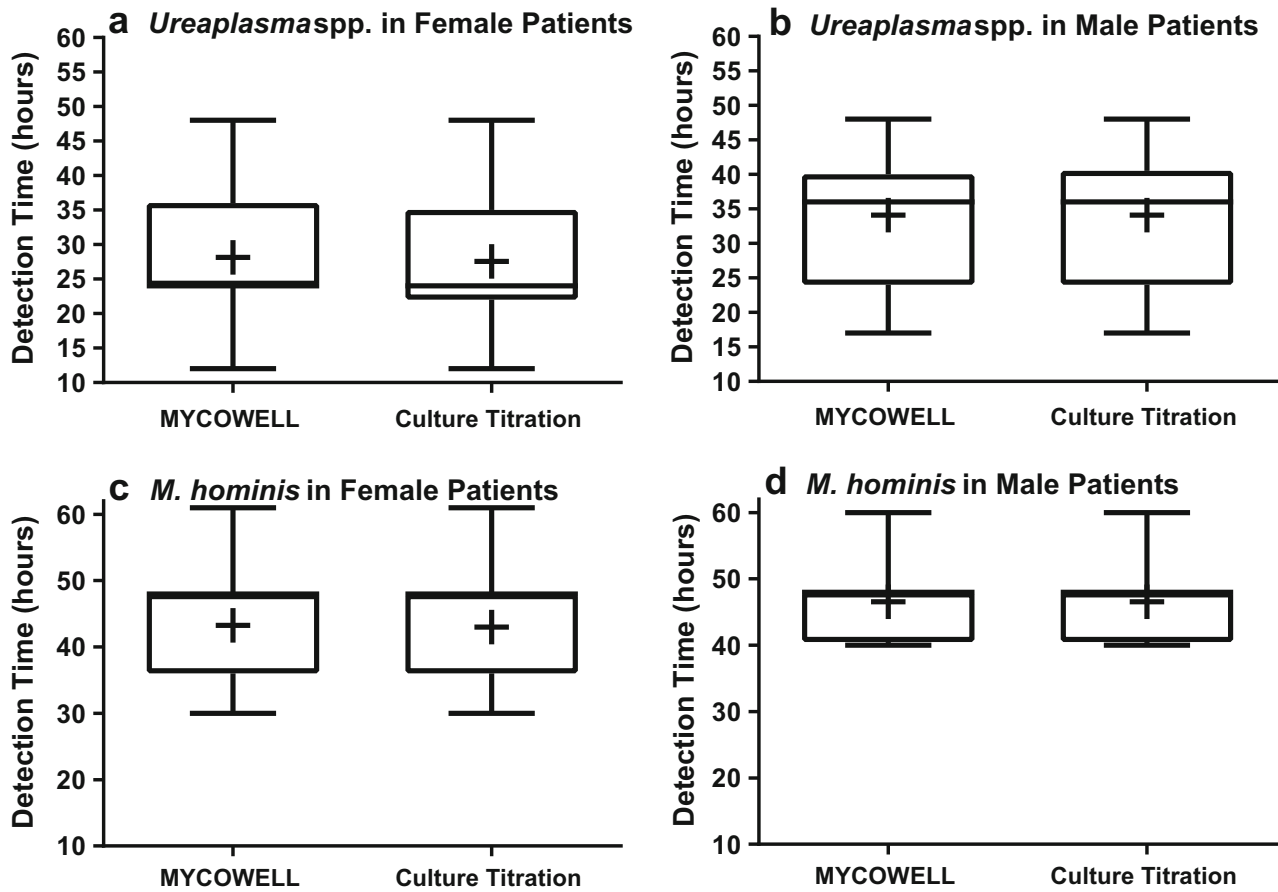

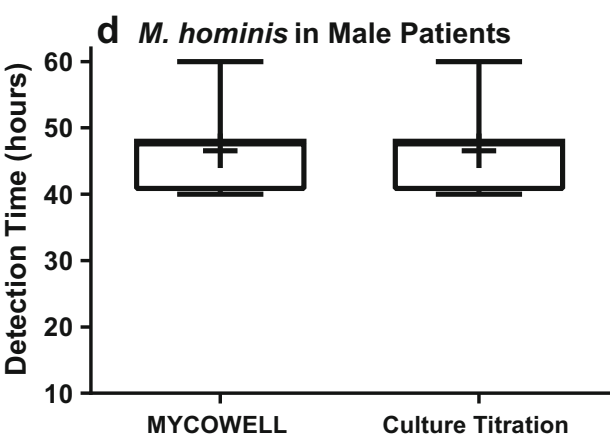

were incubated overnight and read at the earliest convenience the next day and then at regular intervals until $72 \mathrm{~h}$. For the culture titration assay, the mean detection time for Ureaplasma spp. in female patient samples was $28.14 \mathrm{~h}$ post-incubation. Whereas for the MYCO WELL D-ONE, the mean time to detection for Ureaplasma spp. in female patients was $27.57 \mathrm{~h}$ post-incubation. The mean detection time for Ureaplasma spp. in male patient samples was $34.09 \mathrm{~h}$ for both assays. Statistical analysis (ANOVA followed by posthoc analysis using Bonferroni correction) found no difference between methods within genders, but that Ureaplasma spp. was identified significantly faster for female patients $(p<0.001)$ than for male patients by either method, and significance was removed if swab samples were excluded from the analysis. For $M$. hominis, the mean detection time in female patient samples was 43.26 and $43.00 \mathrm{~h}$ for the MYCO WELL D-ONE and culture titration assay, respectively. Whereas for the detection of M. hominis in male samples, the mean time to a positive result was $46.54 \mathrm{~h}$ for both assays. Statistical analysis found no difference for detection time between genders or methodologies, but that Ureaplasma spp. was detected a full day faster than $M$. hominis by any culture method $(p<0.0001)$.

\section{Discussion}

As the body of evidence associating Ureaplasma spp. and $M$. hominis with urogenital pathologies continues to grow, tools capable of accurately detecting these organisms - particularly in the low-resource environments of genitourinary medicine clinics - have the potential to offer clinicians a more comprehensive view of the microbial status of symptomatic patients in the absence of more traditional sexual health pathogens (chlamydia, gonorrhoea, M. genitalium, etc.). Additionally, the inherent antibiotic-resistant nature of these organisms increases the risk of the empirical treatment approaches employed to treat symptomatic non-gonococcal urogenital infections failing. Therefore, systems capable of reliably detecting and concurrently screening these organisms against a panel of commonly prescribed antimicrobials will be valuable in instances to perform proper epidemiological evaluations of the pathogenic potential of these organisms. Additionally, the added information provided by these assays will allow screening for resistance to the subset of antimicrobials that are effective to treat these infections.

For the detection of Ureaplasma spp., the MYCO WELL D-ONE has overall sensitivity and specificity of $91.98 \%$ and 96.44\%, compared with multiplex qPCR. This is consistent with a publication comparing PCR with Mycotest (Bioprepare), showing sensitivity and specificity of $92.4 \%$ and $93.8 \%$, respectively [40]. However, wide-ranging sensitivities and specificities for culture-based Ureaplasma detection methods versus PCR have been published. For example, the sensitivity of the Mycoplasma IST2 (Biomerieux) compared with a commercially available PCR (Anyplex II; Seegene) was only $44.9 \%$, with a specificity of $87.9 \%$ [41]. A previous publication by Favalli et al. has compared the detection of the MYCO WELL D-ONE to the commercial detection kit Anyplex II [42]. These authors were able to evaluate the extended capacity of the kit to detect non-Mollicutes and found excellent concordance in detecting 33/39 
Gardnerella vaginalis and 3/3 Trichomonas vaginalis infections. They found slightly lower Mycoplasma hominis values (sensitivity $71.4 \%$; sensitivity $90.7 \%$ ) and significantly lower values for Ureaplasma spp. (48.98\% and $93.4 \%$ for sensitivity and specificity respectively, compared to ours at $91.98 \%$ and $96.44 \%$ ). These relatively low values were due to 4 positives on MYCO WELL D-ONE not detected by Anyplex II, and demonstrates the limitations of a small sample number $(N=$ $110)$ and comparison to only one detection method that was neither quantitative nor regarded as a clinical diagnostic gold standard. We adopted a novel method of confirming colour changed wells by direct subculture and qPCR, which routinely supported the highly sensitive detection of the MYCO WELL D-ONE when load was too low to be detected by our other methods. This highlights the importance of confirming positive cultures with molecular methods to properly categorise ostensibly false positive culture results. For the detection of $M$. hominis, the overall sensitivity and specificity was $78.23 \%$ and $98.84 \%$, respectively. As a limitation to all molecular detection methods, Favalli et al. were also unable to evaluate the antimicrobial susceptibility screening function of the MYCO WELL D-ONE assay. When comparing PCR with culture, Petrikkos et al. found a $29.6 \%$ reduction in detection sensitivity between Ureaplasma spp. and M. hominis with sensitivity declining from $92.4 \%$ for Ureaplasma spp. to $62.8 \%$ for M. hominis. Similarly, the sensitivity of the MYCO WELL D-ONE declined by $13.75 \%$, from $91.98 \%$ for the detection of Ureaplasma spp. to $78.23 \%$ for the detection of M. hominis. Petrikkos and colleagues also reported that the specificity for $M$. hominis detection remained in relatively high concordance with molecular methods, at $98.8 \%$. Comparable results are presented here with $M$. hominis specificity being calculated to be $98.84 \%$. Further support for the notion of culture being less sensitive for the detection of $M$. hominis, than it is for the detection of Ureaplasma spp., is offered by Abele-Horn et al.'s sensitivity values for Ureaplasma spp. and M. hominis detection at $91 \%$ and $84 \%$, respectively [43]. The disparity between sensitivity for the culture-based detection of Ureaplasma spp. and M. hominis has not been explained elsewhere, though it has been determined that $M$. hominis are harder to recover by culture-based means than Ureaplasma spp.; recovery rate of Ureaplasma spp. is $95 \%$, compared with a recovery rate of $60 \%$ for $M$. hominis [44]. So, it may simply be that through using culturebased assays, M. hominis is harder to recover than Ureaplasma spp. and is perhaps an indication of their more fastidious nature. Across all sample types, the specificity of $M$. hominis detection by the MYCO WELL D-ONE was consistently $>97 \%$, demonstrating that the assay had an exceptionally low false positive rate.

The performance of the semi-quantitative well for Ureaplasma spp. was unable to be assessed, given an error in our study design. The primary aim of this well is to quantify the Ureaplasma spp. inoculum as CLSI-compliant or not $(\leq$ $10^{4} \mathrm{CCU} / \mathrm{mL}$ ) to minimise the identification false resistance, as it has been previously demonstrated that a failure to correctly quantify Ureaplasma concentrations led to an overreporting of resistance [22]. Unfortunately, we only recorded the results for these wells at $72 \mathrm{~h}$ and were unable to retrospectively re-analyse the data as we had done for the antibiotic susceptibility data where time to detection and time of antibiotic well readings were separately recorded. Given that we did not record the times for the Ureaplasma spp. bacterial load wells, it would be unfair to analyse the accuracy of these results against definitive methods. We tested whether prolonged incubation led to artificial errors by re-examining 25 Ureaplasma isolates at $>10^{5} \mathrm{CCU}$ and $<10^{5} \mathrm{CCU}$ and found that readings at first colour change $(16-18 \mathrm{~h})$ were completely accurate for both antimicrobial resistance and bacterial load, but over-estimate for bacterial load occurred for 8 isolates at $<10^{5} \mathrm{CCU}$ and false antimicrobial resistance was found for 3 isolates at $72 \mathrm{~h}$ as opposed to accurate readings at first organism identification (16-24 h) (data not shown). Therefore, it is critical that these wells not be allowed to over-incubate.

Levofloxacin resistance for Ureaplasma spp. was $0.54 \%$, considerably lower than rates published in other studies. In Minnesota, 250 clinically isolated Ureaplasma spp. subjected to MIC testing determined a levofloxacin resistance rate of $6.4 \%$ and $5.2 \%$ for $U$. parvum and U. urealyticum, respectively [45]. Molecular characterisation of the isolates in the Fernandez et al. study revealed $93 \%$ of levofloxacin-resistant Ureaplasma spp. to possess the parC quinolone-associated resistance mutation, Ser83Leu. Similarly, sequencing of the two levofloxacin-resistant isolates identified here confirmed a Ser83Leu mutation in the $\operatorname{parC}$ gene. This Ser83Leu $\operatorname{parC}$ gene mutation is the most prevalent levofloxacin resistance mechanism identified in Ureaplasma spp. isolates, accounting for up to $87 \%$ of fluoroquinolone resistance [45-48]. Though comparatively low, the levofloxacin resistance rate reported here is not unusual, being concordant in US and French studies: $1.4 \%$ and $1.2 \%$, respectively [49, 50]. Conversely, Song et al. reported levofloxacin resistance for Ureaplasma spp. in China to be $75 \%$ and the most common mechanism of resistance to be mostly conferred by the Ser83Leu $\operatorname{parC}$ mutation [51]. They attributed the high resistance rates to widespread and general use of fluoroquinolones in China. Beeton et al. determined 2/130 isolates to have relative resistance to ciprofloxacin in samples from England in Wales, but to have an MIC $=2 \mathrm{mg} / \mathrm{L}$ for levofloxacin and therefore considered to be below the breakpoint, despite both having the Ser93Leu parC mutation [52]. This coupled with our equivalent findings of $2 /$ 424 isolates having intermediate resistance (MIC $=4 \mathrm{mg} / \mathrm{L}$ levofloxacin) confirm extremely low fluoroquinolone resistance for Ureaplasma spp. in Wales. 
Tetracycline resistance in Ureaplasma spp. was $0.54 \%$, also particularly low. Molecular characterisation of the isolates revealed that both harboured the $\operatorname{Tn} 916 \operatorname{tet}(M)$ conjugated transposon, the only identified mechanism by which Ureaplasma spp. possess tetracycline resistance [53]. Tetracycline resistance rates for Ureaplasma spp. typically range between 0 and $14 \%$ globally: $0 \%$, Croatia [54]; $1 \%$, China [55]; 2\%, Italy [56]; 6\%, Hungary [57]; 14\%, Turkey [58]. Though tetracycline resistance rates as high as $34 \%$ have been published following CLSI-compliant AST of Ureaplasma spp. isolates in the USA [46]. However, more recently, Valentine-King and Brown published a 1.4\% tetracycline resistance rate for Ureaplasma spp. in Florida, USA [49]. Comparatively, screening for tetracycline resistance in Ureaplasma spp. populations in Wales and England has consistently reported rates of $2 \%[22,52]$. The findings of this study show that tet $(M)$ prevalence in Ureaplasma spp. populations throughout Wales have not appreciably increased. Likewise, a 6-year analysis of Ureaplasma spp. isolates in France over a 6-year period (2010-2015) did not note any increase in tet $(M)$ prevalence, $~ 7.5 \%$ [50]. But, previous French data (1999-2002) determined Ureaplasma spp. tetracycline resistance rates to be at $2.2 \%$ [59]. Therefore, whilst no significant change was seen in the most recent 6-year assessment, there has been an overall rise in tetracycline resistance over the last 20 years. This highlights the need for continued antibiotic resistance surveillance for Ureaplasma spp. to track such changes in geographically distinct locations, especially as tetracycline is prescribed as a first-line therapy in the treatment of adult urogenital Ureaplasma spp. infection. For $M$. hominis, 2 tetracycline-resistant isolates were identified giving a relatively low resistance rate of $2 \%$. However, reported resistance for $M$. hominis varies greatly, ranging from 0 to $100 \%$ [60-62]. Though typically, resistance rates are situated between 10 and $40 \%$ of $M$. hominis, globally [63, 64]. Both isolates determined to be tetracycline-resistant harboured the Tn916 tet $(M)$ gene. Like Ureaplasma spp., this is the most described resistance mechanism for tetracycline resistance in M. hominis. However, it is important to note that while a tet $(M)$-positive tetracycline-resistant Ureaplasma parvum and $M$. hominis were both isolated from the same patient (DF28), sequence identity of the genes was only 1896/1920 bp, indicating they had acquired the gene independently. Whilst the rate of tetracycline resistance for South Wales $M$. hominis is relatively low, examples of rates between 0 and $5 \%$ are not uncommon $[65,66]$. Analysis of the MYCO WELL D-ONE showed good concordance with traditional methods of susceptibility testing, with only a minor number of false identification of levofloxacin and moxifloxacin resistance in Ureaplasma spp., and clindamycin resistance for $M$. hominis. A note of caution needs to be emphasized that the antimicrobial resistance does give much higher false positive rates if not recorded concurrently at the time the species identification wells first turn red. However, with the differential time to positivity for the two separate bacterial species (Fig. 6), this can become quite complicated. Irrespective, it is always important that any putative resistant results should always have an accurate MIC determined for confirmation using CLSI compliant methodologies, and any commercial assay should only be used as an initial screening method for controlled epidemiological studies.

For culture-based assays to successfully and concurrently detect genital mycoplasmas and screen for antibiotic resistance, CLSI-compliant bacterial titres are required $(<$ $10^{5} \mathrm{CCU} / \mathrm{mL}$ ) [21]. Accordingly, bacterial titres between sample types were investigated, revealing swabs to consistently produce titres $>10^{5} \mathrm{CCU} / \mathrm{mL}$ for both Ureaplasma spp. and $M$. hominis, following resuspension in $10 \mathrm{~mL}$ of saline (Fig. 4), which was particularly striking for matched urine/ swab sample analysis (Fig. 5). The comparable sensitivities and specificities for the detection of Ureaplasma spp. and $M$. hominis (Tables 1 and 2) between sample types coupled with the differences in bacterial load suggest that urine samples are the preferred option for concurrent cultured-based detection and CLSI-complaint AST of genital mycoplasmas.

Whilst the designation of Ureaplasma spp. and M. hominis as pathogen, commensal or pathobiont remains variable, tools that facilitate their identification may aid in resolving such controversy. The MYCO WELL D-ONE displays high sensitivity and specificity values for the detection of Ureaplasma spp., with the results being comparable to the widely-used Abbott real-time PCR for the detection of $C$. trachomatis (sensitivity, 92,4\%; specificity 99.2\%) [67]. Though MYCOWELL D-ONE $M$. hominis sensitivity decreased slightly; this is seemingly a universal difference in the ability of culture-based methods to recover these organisms. This does not negate the effectiveness of this assay to detect $M$. hominis infection, evidenced by the high values seen across specificity, PPV, NPV and accuracy. Whilst qPCR remains the preferred detection method due to its increased sensitivity and ability to speciate Ureaplasma infections, the current European guidelines state routine screening for these organisms is undesirable in lieu of substantiating that the treatment of asymptomatic genital mycoplasma infection is beneficial. Therefore, the sample numbers required to facilitate economically viable high-throughput molecular testing for genital mycoplasmas, as is currently performed for STIs such as $C$. trachomatis, are not investigated. In instances of symptomatic non-gonococcal urogenital pathologies, assays such as the MYCO WELL D-ONE provide a simple, economic and accurate method for determining the presence of Ureaplasma spp. or M. hominis in the urogenital tract. Accordingly, it allows clinicians a more comprehensive view of the urogenital microbiome underlying certain pathologies, further elucidating the aetiology of non-gonococcal urethritis, facilitating better-informed guided therapy. This may help to alleviate 
the concerns of empirical treatments fuelling the generation of multi-drug resistant urogenital pathogens [68] and avoid inappropriate empirical treatment for NGU in cohorts where Ureaplasma spp. may be the causative agent [69]. The geographic variability of antimicrobial resistance rates for these organisms highlights the need to continually survey populations for trends in resistance. Whilst the MYCO WELL DONE offers a useful presumptive screening method, the need to affirm the result through CLSI-compliant means, or determination of underlying molecular methods of antimicrobial resistance, to prevent the over-reporting of antimicrobial resistance is essential [20, 22].

Acknowledgements This study was funded by the Knowledge Economy Skills Scholarships (KESS 2) supported by European Social Funds (ESF) through the Welsh Government (grant 513674). We would also like to thank all the research and staff nurses at Dewi Sant, Keir Hardy and Ysbyty Cwm Cynon for their willingness, enthusiasm and tireless efforts in consenting and collecting patient samples. Further thanks are extended to all patients who participated in the study. Many thanks to Beth Phillips, University of Wales press, for editorial help.

Funding information This study was funded by the Knowledge Economy Skills Scholarships (KESS 2) supported by European Social Funds (ESF) through the Welsh Government (grant 513674).

Data Availability Available upon reasonable request from the corresponding author.

\section{Compliance with ethical standards}

Conflict of interest The authors declare that they have no conflict of interest.

Ethics approval This study was granted approval by the NHS Heath Research Authority (IRAS 230693) for studies on participants giving informed consent.

Open Access This article is licensed under a Creative Commons Attribution 4.0 International License, which permits use, sharing, adaptation, distribution and reproduction in any medium or format, as long as you give appropriate credit to the original author(s) and the source, provide a link to the Creative Commons licence, and indicate if changes were made. The images or other third party material in this article are included in the article's Creative Commons licence, unless indicated otherwise in a credit line to the material. If material is not included in the article's Creative Commons licence and your intended use is not permitted by statutory regulation or exceeds the permitted use, you will need to obtain permission directly from the copyright holder. To view a copy of this licence, visit http://creativecommons.org/licenses/by/4.0/.

\section{References}

1. Bhimji SS, Unakal CG (2017) Bacteria, Gram Positive. StatPearls Publishing

2. McCormack WM (1993) Susceptibility of mycoplasmas to antimicrobial agents: clinical implications. Clin Infect Dis 17(Suppl 1): S200-S201
3. Bermingham A, Derrick JP (2002) The folic acid biosynthesis pathway in bacteria: evaluation of potential for antibacterial drug discovery. BioEssays 24:637-648. https://doi.org/10.1002/bies.10114

4. Pereyre S, Gonzalez P, De Barbeyrac B, Darnige A, Renaudin H, Charron A et al (2002) Mutations in 23S rRNA account for intrinsic resistance to macrolides in Mycoplasma hominis and Mycoplasma fermentans and for acquired resistance to macrolides in M. hominis. Antimicrob Agents Chemother 46:3142-3150. https://www.ncbi. nlm.nih.gov/pmc/articles/PMC128781/pdf/0261.pdf. https://doi. org/10.1128/AAC.46.10.3142-3150.2002

5. Martin DH (2008) Nongonococcal urethritis: New views through the prism of modern molecular microbiology. Curr Infect Dis Rep 10:128-132. https://link.springer.com/content/pdf/10.1007\% 2Fs11908-008-0023-x.pdf. https://doi.org/10.1007/s11908-0080023-x

6. Wetmore CM, Manhart LE, Lowens MS, Golden MR, Whittington WLH, Xet-Mull AM et al (2011) Demographic, behavioral, and clinical characteristics of men with nongonococcal urethritis differ by etiology: a case-comparison study. Sex Transm Dis 38:180-186. http://www.ncbi.nlm.nih.gov/pubmed/21285914. https://doi.org/ 10.1097/OLQ.0b013e3182040de9

7. Schlicht MJ, Lovrich SD, Sartin JS, Karpinsky P, Callister SM, Agger WA (2004) High prevalence of genital mycoplasmas among sexually active young adults with urethritis or cervicitis symptoms in La Crosse, Wisconsin. J Clin Microbiol 42:4636-4640. http:// www.ncbi.nlm.nih.gov/pubmed/15472322. https://doi.org/10. 1128/JCM.42.10.4636-4640.2004

8. Chaim W, Horowitz S, David JB, Ingel F, Evinson B, Mazor M (2003) Ureaplasma urealyticum in the development of postpartum endometritis. Eur J Obstet Gynecol Reprod Biol 109:145-148. http://www.ncbi.nlm.nih.gov/pubmed/12860331. https://doi.org/ 10.1016/S0301-2115(03)00007-1

9. Yoon BH, Romero R, Park JS, Chang JW, Kim Y a, Kim JC et al (1998) Microbial invasion of the amniotic cavity with Ureaplasma urealyticum is associated with a robust host response in fetal, amniotic, and maternal compartments. Am J Obstet Gynecol 179: 1254-1260. https://doi.org/10.1016/S0002-9378(98)70142-5

10. Spiegel CA (1991) Bacterial vaginosis. Clin Microbiol Rev 4:485502. http://www.ncbi.nlm.nih.gov/pubmed/1747864. https://doi. org/10.1128/CMR.4.4.485

11. Mårdh PA, Weström L (1970) Tubal and cervical cultures in acute salpingitis with special reference to Mycoplasma hominis and Tstrain mycoplasmas. Br J Vener Dis 46:179-186

12. Witkin SS, Minis E, Athanasiou A, Leizer J, Linhares IM (2017) Chlamydia trachomatis: the persistent pathogen. Clin Vaccine Immunol 24. https://doi.org/10.1128/cvi.00203-17

13. Horner P, Donders G, Cusini M, Gomberg M, Jensen JS, Unemo M (2018) Should we be testing for urogenital mycoplasma hominis, Ureaplasma parvum and Ureaplasma urealyticum in men and women? - a position statement from the European STI guidelines editorial board. J Eur Acad Dermatology Venereol 32:1845-1851. https://doi.org/10.1111/jdv.15146

14. Shimada Y, Ito S, Mizutani K, Sugawara T, Seike K, Tsuchiya T et al (2014) Bacterial loads of Ureaplasma urealyticum contribute to development of urethritis in men. Int J STD AIDS 25:294-298. https://doi.org/10.1177/0956462413504556

15. Deguchi T, Yoshida T, Miyazawa T, Yasuda M, Tamaki M, Ishiko $\mathrm{H}$ et al (2004) Association of Ureaplasma urealyticum (Biovar 2) with Nongonococcal Urethritis. Sex Transm Dis 31:192-195. http://content.wkhealth.com/linkback/openurl?sid=WKPTLP: landingpage \&an=00007435-200403000-00011. https://doi.org/10. 1097/01.OLQ.0000114653.26951.71

16. Cox C, Watt AP, McKenna JP, Coyle PV (2016) Mycoplasma hominis and Gardnerella vaginalis display a significant synergistic relationship in bacterial vaginosis. Eur J Clin Microbiol Infect Dis 35:481-487. https://doi.org/10.1007/s10096-015-2564-x 
17. Beeton ML, Payne MS, Jones L (2019) The role of Ureaplasma spp. in the development of Nongonococcal urethritis and infertility among men. Clin Microbiol Rev 32. https://doi.org/10.1128/cmr. 00137-18

18. Miles RJ (1992) Catabolism in Mollicutes. J Gen Microbiol 138: 1773-1783. https://doi.org/10.1099/00221287-138-9-1773

19. Xiao L, Glass JI, Paralanov V, Yooseph S, Cassell GH, Duffy LB et al (2010) Detection and characterization of human Ureaplasma species and serovars by real-time PCR. J Clin Microbiol 48:27152723. https://doi.org/10.1128/JCM.01877-09

20. Beeton ML, Spiller OB (2017) Antibiotic resistance among Ureaplasma spp. isolates: cause for concern? J Antimicrob Chemother 72:330-337. https://doi.org/10.1093/jac/dkw425

21. CLSI (2011) Methods for antimicrobial susceptibility testing for human Mycoplasmas; Approved Guideline. CLSI document M43-A. Clinical and Laboratory Standards Institute, Wayne

22. Beeton ML, Chalker VJ, Maxwell NC, Kotecha S, Spiller OB (2009) Concurrent titration and determination of antibiotic resistance in Ureaplasma species with identification of novel point mutations in genes associated with resistance. Antimicrob Agents Chemother 53:2020-2027. https://doi.org/10.1128/AAC.01349-08

23. Huang C, Long X, Jing S, Fan L, Xu K, Wang S et al (2016) Ureaplasma urealyticum and Mycoplasma hominis infections and semen quality in 19,098 infertile men in China. World J Urol 34: 1039-1044. https://link.springer.com/content/pdf/10.1007\% 2Fs00345-015-1724-z.pdf. https://doi.org/10.1007/s00345-0151724-z

24. Payne MS, Goss KCW, Connett GJ, Legg JP, Bruce KD, Chalker V (2012) A quantitative analysis of Ureaplasma urealyticum and Ureaplasma parvum compared with host immune response in preterm neonates at risk of developing bronchopulmonary dysplasia. J Clin Microbiol 50:909-914. http://www.ncbi.nlm.nih.gov/pubmed/ 22189123. https://doi.org/10.1128/JCM.06625-11

25. Férandon C, Peuchant O, Janis C, Benard A, Renaudin H, Pereyre S et al (2011) Development of a real-time PCR targeting the yidC gene for the detection of Mycoplasma hominis and comparison with quantitative culture. Clin Microbiol Infect 17:155-159. https://doi.org/10.1111/j.1469-0691.2010.03217.x

26. Krueger F (2015) Trim Galore!: Wrapper script to automate quality and adapter trimming [Online]. Available online at: http://www. bioinformatics.babraham.ac.uk/projects/trim_galore/

27. Andrews S (2010) FastQC: A quality control tool for high throughput sequence data [Online]. Available online at: http://www. bioinformatics.babraham.ac.uk/projects/fastqc/

28. Magoč T, Salzberg SL (2011) FLASH: fast length adjustment of short reads to improve genome assemblies. Bioinformatics 27: 2957-2963. https://doi.org/10.1093/bioinformatics/btr507

29. Bankevich A, Nurk S, Antipov D, Gurevich AA, Dvorkin M, Kulikov AS et al (2012) SPAdes: a new genome assembly algorithm and its applications to single-cell sequencing. J Comput Biol 19:455-477. https://doi.org/10.1089/cmb.2012.0021

30. Li H, Durbin R (2009) Fast and accurate short read alignment with burrows-wheeler transform. Bioinformatics 25:1754-1760. https:// doi.org/10.1093/bioinformatics/btp324

31. Walker BJ, Abeel T, Shea T, Priest M, Abouelliel A, Sakthikumar S et al (2014) Pilon: an integrated tool for comprehensive microbial variant detection and genome assembly improvement. PLoS One 9. https://doi.org/10.1371/journal.pone.0112963

32. Gurevich A, Saveliev V, Vyahhi N, Tesler G (2013) QUAST: quality assessment tool for genome assemblies. Bioinformatics 29: 1072-1075. https://doi.org/10.1093/bioinformatics/btt086

33. McArthur AG, Waglechner N, Nizam F, Yan A, Azad MA, Baylay AJ et al (2013) The comprehensive antibiotic resistance database. Antimicrob Agents Chemother 57:3348-3357. https://doi.org/10. 1128/AAC.00419-13
34. Hasman H, Saputra D, Sicheritz-Ponten T, Lund O, Svendsen CA, Frimodt-Moller $\mathrm{N}$ et al (2014) Rapid whole-genome sequencing for detection and characterization of microorganisms directly from clinical samples. J Clin Microbiol 52:139-146. https://doi.org/10. 1128/JCM.02452-13

35. Seemann T (2014) Prokka: rapid prokaryotic genome annotation. Bioinformatics 30:2068-2069. https://doi.org/10.1093/ bioinformatics/btu153

36. McGinnis S, Madden TL (2004) BLAST: at the core of a powerful and diverse set of sequence analysis tools. Nucleic Acids Res 32: 20-25. https://doi.org/10.1093/nar/gkh435

37. Gupta SK, Padmanabhan BR, Diene SM, Lopez-Rojas R, Kempf M, Landraud L et al (2014) ARG-annot, a new bioinformatic tool to discover antibiotic resistance genes in bacterial genomes. Antimicrob Agents Chemother 58:212-220. https://doi.org/10. 1128/AAC.01310-13

38. Inouye M, Dashnow H, Raven LA, Schultz MB, Pope BJ, Tomita T et al (2014) SRST2: rapid genomic surveillance for public health and hospital microbiology labs. Genome Med 6:1-16. https://doi. org/10.1186/s13073-014-0090-6

39. Chen L, Yang J, Yu J, Yao Z, Sun L, Shen Y et al (2005) VFDB: a reference database for bacterial virulence factors. Nucleic Acids Res 33:325-328. https://doi.org/10.1093/nar/gki008

40. Petrikkos GL, Hadjisoteriou M, Daikos GL (2007) PCR versus culture in the detection of vaginal Ureaplasma urealyticum and Mycoplasma hominis. Int J Gynecol Obstet 97:202-203. https:// doi.org/10.1016/j.ijgo.2006.12.014

41. Choe H-S, Lee DS, Lee S-J, Hong S-H, Park DC, Lee M-K et al (2013) Performance of Anyplex ${ }^{\mathrm{TM}}$ II multiplex real-time PCR for the diagnosis of seven sexually transmitted infections: comparison with currently available methods. Int J Infect Dis 17:e1134-e1140. https://doi.org/10.1016/j.ijid.2013.07.011

42. Favalli C, Favaro M, Santi F, Piperno M, D’Agostini C, Ciotti M (2018) Performance evaluation of a new culture colorimetric detection assay. Eurasian J Med. http://www.eajm.org/eng/makale/3062/ 196/Full-Text. https://doi.org/10.5152/eurasianjmed.2018.17364

43. Abele-Horn M, Wolff C, Dressel P, Zimmermann A, Vahlensieck W, Pfaff $F$ et al (1996) Polymerase chain reaction versus culture for detection of ureaplasma urealyticum and mycoplasma hominis in the urogenital tract of adults and the respiratory tract of newborns. Eur J Clin Microbiol Infect Dis 15:595-598. https://doi.org/10. 1007/BF01709369

44. Cavicchini S, Biffi MR, Brezzi A, Alessi E (1989) Mycoplasma hominis and Ureaplasma urealyticum. Comparison of media for isolation and prevalence among patients with nongonococcal nonchlamydial genital infections. G Ital di Dermatologia e Venereol 124:321-324 http://www.ncbi.nlm.nih.gov/pubmed/ 2628275

45. Fernández J, Karau MJ, Cunningham SA, Greenwood-Quaintance KE, Patel R (2016) Antimicrobial susceptibility and clonality of clinical Ureaplasma isolates in the United States. Antimicrob Agents Chemother 60:4793-4798. https://doi.org/10.1128/AAC. 00671-16

46. Li X, Crabb DM, Duffy LB, Paralanov V, Glass JI, Waites KB (2012) Chromosomal mutations responsible for fluoroquinolone resistance in Ureaplasma species in the United States. Antimicrob Agents Chemother 56:2780-2783. http://www.ncbi.nlm.nih.gov/ pubmed/22371892. https://doi.org/10.1128/AAC.06342-11

47. Beeton ML, Chalker VJ, Kotecha S, Spiller OB (2009) Comparison of full gyrA, gyrB, parC and parE gene sequences between all Ureaplasma parvum and Ureaplasma urealyticum serovars to separate true fluoroquinolone antibiotic resistance mutations from nonresistance polymorphism. J Antimicrob Chemother 64. https://doi. org/10.1093/jac/dkp218

48. Kawai Y, Nakura Y, Wakimoto T, Nomiyama M, Tokuda T, Takayanagi $\mathrm{T}$ et al (2015) In vitro activity of five quinolones and 
analysis of the quinolone resistance-determining regions of gyrA, gyrB, parC, and parE in Ureaplasma parvum and Ureaplasma urealyticum clinical isolates from perinatal patients in Japan. Antimicrob Agents Chemother 59:2358-2364. https://doi.org/10. 1128/AAC.04262-14

49. Valentine-King MA, Brown MB (2017) Antibacterial resistance in Ureaplasma species and mycoplasma hominis isolates from urine cultures in college-aged females. Antimicrob Agents Chemother 61. https://doi.org/10.1128/aac.01104-17

50. Meygret A, Le Roy C, Renaudin H, Bébéar C, Pereyre S (2018) Tetracycline and fluoroquinolone resistance in clinical Ureaplasma spp. and Mycoplasma hominis isolates in France between 2010 and 2015. J Antimicrob Chemother 73:2696-2703. https://doi.org/10. 1093/jac/dky238

51. Song J, Qiao Y, Kong Y, Ruan Z, Huang J, Song T et al (2015) Frequent topoisomerase IV mutations associated with fluoroquinolone resistance in Ureaplasma species. J Med Microbiol 64:13151320. https://doi.org/10.1099/jmm.0.000153

52. Beeton ML, Chalker VJ, Jones LC, Maxwell NC, Spiller OB (2016) Antibiotic resistance among clinical Ureaplasma isolates recovered from neonates in England and Wales between 2007 and 2013. Antimicrob Agents Chemother 60:52-56. https://doi.org/10. 1128/AAC.00889-15

53. Mardassi BBA, Aissani N, Moalla I, Dhahri D, Dridi A, Mlik B (2012) Evidence for the predominance of a single tet(M) gene sequence type in tetracycline-resistant Ureaplasma parvum and Mycoplasma hominis isolates from Tunisian patients. J Med Microbiol 61:1254-1261. http://www.ncbi.nlm.nih.gov/pubmed/ 22580915. https://doi.org/10.1099/jmm.0.044016-0

54. Hunjak B, Sabol I, Vojnović G, Fistonić I, Erceg AB, Peršić Z et al (2014) Ureaplasma urealyticum and Ureaplasma parvum in women of reproductive age. Arch Gynecol Obstet 289:407-412. https://doi. org/10.1007/s00404-013-2980-Z

55. Song T, Ye A, Xie X, Huang J, Ruan Z, Kong Y et al (2014) Epidemiological investigation and antimicrobial susceptibility analysis of ureaplasma species andMycoplasmahominis in outpatients with genital manifestations. J Clin Pathol 67:817-820. https://doi. org/10.1136/jclinpath-2014-202248

56. Messano GA, Cancrini F, Marsella LT (2014) Antibiotic resistance and defensive medicine, a modern challenge for an old problem: the case of Ureaplasma urealyticum. Ig Sanita Pubbl 70:295-304

57. Pónyai K, Mihalik N, Ostorházi E, Farkas B, Párducz L, Marschalkó M et al (2013) Incidence and antibiotic susceptibility of genital mycoplasmas in sexually active individuals in Hungary. Eur J Clin Microbiol Infect Dis 32:1423-1426. http://www.ncbi. nlm.nih.gov/pubmed/23686458. https://doi.org/10.1007/s10096013-1892-y

58. Karabay O, Topcuoglu A, Kocoglu E, Gurel S, Gurel H, Ince NK (2006) Prevalence and antibiotic susceptibility of genital Mycoplasma hominis and Ureaplasma urealyticum in a university hospital in Turkey. Clin Exp Obstet Gynecol 33:36-38 http://www. ncbi.nlm.nih.gov/pubmed/16761537

59. Dégrange S, Renaudin H, Charron A, Bébéar C, Bébéar CM (2008) Tetracycline resistance in Ureaplasma spp. and Mycoplasma hominis: prevalence in Bordeaux, France, from 1999 to 2002 and description of two tet(M)-positive isolates of M. hominis susceptible to tetracyclines. Antimicrob Agents Chemother 52: 742-744. http://www.ncbi.nlm.nih.gov/pubmed/18025113. https:// doi.org/10.1128/AAC.00960-07

60. Skiljevic D, Mirkov D, Vukicevic J (2016) Prevalence and antibiotic susceptibility of Mycoplasma hominis and Ureaplasma urealyticum in genital samples collected over 6 years at a Serbian university hospital. Indian J Dermatol Venereol Leprol 82:37. http:// www.ncbi.nlm.nih.gov/pubmed/26728808. https://doi.org/10. 4103/0378-6323.172903

61. Bayraktar MR, Ozerol IH, Gucluer N, Celik O (2010) Prevalence and antibiotic susceptibility of Mycoplasma hominis and Ureaplasma urealyticum in pregnant women. Int J Infect Dis 14: e90-5. https://www.sciencedirect.com/science/article/pii/ S1201971209001568. https://doi.org/10.1016/j.ijid.2009.03.020

62. Kechagia N, Bersimis S, Chatzipanagiotou S (2008) Incidence and antimicrobial susceptibilities of genital mycoplasmas in outpatient women with clinical vaginitis in Athens, Greece. J Antimicrob Chemother 62:122-125. https://doi.org/10.1093/jac/dkn158

63. Waites KB, Katz B, Schelonka RL (2005) Mycoplasmas and ureaplasmas as neonatal pathogens. Clin Microbiol Rev 18:757789. https://doi.org/10.1128/CMR.18.4.757-789.2005

64. Taylor-Robinson D (2002) Antibiotic susceptibilities of mycoplasmas and treatment of mycoplasmal infections. J Antimicrob Chemother 40:622-630. https://doi.org/10.1093/jac/40.5.622

65. Ye G, Jiang Z, Wang M, Huang J, Jin G, Lu S (2014) The resistance analysis of Ureaplasma urealyticum and Mycoplasma hominis in female reproductive tract specimens. Cell Biochem Biophys 68: 207-210. http://www.ncbi.nlm.nih.gov/pubmed/23749559. https:// doi.org/10.1007/s12013-013-9691-8

66. Ling Y, Wu T, Hou Y, Cheng X, Zhu C, Liu J et al (2012) Prevalence and antimicrobial susceptibility of Ureaplasma urealyticum and Mycoplasma hominis in Chinese women with genital infectious diseases. Indian J Dermatology, Venereol Leprol 78:406. http://www.ijdvl.com/text.asp?2012/78/3/406/ 95480. https://doi.org/10.4103/0378-6323.95480

67. Gaydos CA, Cartwright CP, Colaninno P, Welsch J, Holden J, Ho SY et al (2010) Performance of the Abbott realtime CT/NG for detection of Chlamydia trachomatis and Neisseria gonorrhoeae. J Clin Microbiol 48:3236-3243. https://doi.org/10.1128/JCM. 01019-10

68. Bader MS, Loeb M, Brooks AA (2016) An update on the management of urinary tract infections in the era of antimicrobial resistance. Postgrad Med 129:242-258. https://doi.org/10.1080/00325481. 2017.1246055

69. Stamm WE, Batteiger BE, McCormack WM, Totten PA, Sternlicht A, Kivel NM (2007) A randomized, double-blind study comparing single-dose rifalazil with single-dose azithromycin for the empirical treatment of nongonococcal urethritis in men. Sex Transm Dis 34: 545-552. https://insights.ovid.com/crossref?an $=00007435$ 900000000-99684. https://doi.org/10.1097/01.olq.0000253348. $44308.8 \mathrm{c}$

Publisher's note Springer Nature remains neutral with regard to jurisdictional claims in published maps and institutional affiliations. 